\section{Early prenatal diagnosis of diastrophic dwarfism by ultrasound}

Several forms of dwarfism are hereditary. One such is diastrophic dwarfism, which is inherited as an autosomal recessive. There is a need for early prenatal diagnosis of these conditions, but no satisfactory method has been available until now. We describe a patient in whom ultrasonic measurements of fetal limb length were compared with normal values. ${ }^{1}$ Occasionally, as in this case, fetoscopy may be used to confirm the diagnosis.

\section{Case report}

A 28-year-old Caucasian gravida 2, para 1, was referred for ultrasound examination to rule out possible diastrophic dwarfism syndrome in her present pregnancy. She had delivered an affected baby two years previously.

The first ultrasound examination, performed at a menstrual age of 13 weeks and 5 days, showed a crown-rump length of $43 \mathrm{~mm}$ corresponding to a gestational age of 11 weeks. Three weeks later a repeat ultrasound examination using the Kretz Combison 100 real-time scanner confirmed the gestational age determined by ultrasound. The limbs were examined but our difficulty in defining their outline at this gestation suggested that there was an abnormality. A femur length of $9 \mathrm{~mm}$ was recorded (normal range $13-20 \mathrm{~mm}^{1}$ ).

Two weeks later, at 16 weeks' gestation, a further scan was performed to confirm this suspicion. Again, there was some difficulty in defining the limbs but we obtained a reproducible femur length measurement of $13 \mathrm{~mm}$ (normal range 19-26 $\mathrm{mm}^{1}$ ). This was well below the expected range for the period of gestation and dwarfism was diagnosed on the basis of considerably shortened femur measurements. We decided to verify this and to assess the severity of the condition by fetoscopy.

At fetoscopy we obtained good visualisation of the fetus. The limbs were extremely short and curved and examination of the face and oral cavity showed micrognathia and cleft palate. These features were consistent with diastrophic dwarfism.

The patient elected to terminate the pregnancy and postmortem examination of the fetus confirmed the diagnosis. The limb deformities are illustrated in the radiograph (figure): there is gross shortening of the long bones and the varus deformities are evident.

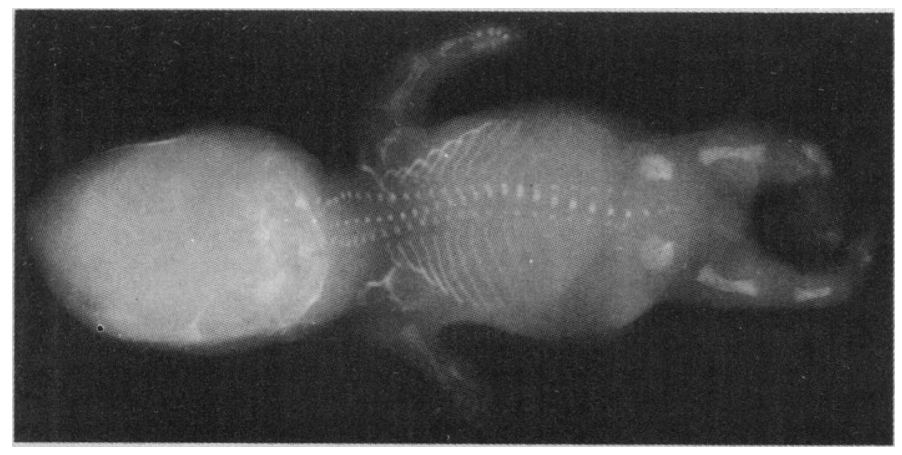

Radiograph showing limb deformities of diastrophic dwarfism.

\section{Comment}

Definitive prenatal detection of congenital limb deformities has until now been confined mainly to radiology and fetoscopy. Radiology is reliable only later in pregnancy and carries a small risk of irradiation to the fetus. Omenn $e t a l^{2}$ reported using $x$ rays between 16 and 18 weeks' gestation to rule out hereditary skeletal dysplasia in seven cases, but no positive diagnosis was made.

Fetoscopy permits direct examination of the fetus but is invasive and has a $3-5 \%$ fetal mortality. ${ }^{3}$ The assessment of proportion-for example, abnormal facies or minor limb reduction-is difficult, but discrete limb abnormalities or cleft palate can be identified with confidence. Fetoscopy has also been used to establish the presence of spina bifida ${ }^{4}$ and of an extra digit in Ellis-van Creveld syndrome. ${ }^{5}$

Ultrasound is non-invasive and can be repeated with safety. The newer, high-resolution real-time scanners have made it possible to establish a normal range for limb length early in gestation. ${ }^{1}$ Thus gross deformities can be diagnosed, as illustrated in this case. They can also be excluded in patients at risk of carrying a fetus with these deformities. As confidence with this technique increases, the need for fetoscopy will diminish.

Real-time scanning is fast and can be performed with relative ease. Although the incidence of congenital limb deformities in the general population is low, screening for these disorders is feasible: measurement of limb length will probably become part of every fetus's physical examination during the second trimester.

We thank Dr Hughes-Nurse and Dr D M Johnston of Peterborough for permission to report this case, $\operatorname{Dr} M$ Driver for performing the necropsy, and the radiography department for taking the radiograph.

${ }^{1}$ Queenan JT, O'Brien GD, Campbell S. Ultrasound determination of fetal limb bone length. Am $\mathcal{F}$ Obstet Gynecol (in press).

2 Omenn GS, Hall JG, Graham B, Harp L. The use of radiographic visualisation for prenatal diagnosis. In: Bergsma $D$, Lowry RB, eds. Embryology and pathogenesis and prenatal diagnosis. New York: Allan $\mathbf{R}$ Liss, 1977: 217-29.

${ }^{3}$ Rodeck CH. Fetoscopy guided by real-time ultrasound for pure fetal blood samples, fetal skin samples and examination of the fetus. Br $\mathcal{f}$ Obstet Gynaecol (in press).

- Rodeck CH, and Campbell S. Early prenatal diagnosis of neural tube defects by ultrasound-guided fetoscopy. Lancet 1978;i:1128-9.

${ }^{5}$ Mahoney MJ, Hobbins JC. Prenatal diagnosis of ehondroectodermal dysplasia (Ellis-van Creveld syndrome) with fetoscopy and ultrasound. New Engl f Med 1977;297:258-60.

(Accepted 28 fanuary 1980)

Department of Obstetrics and Gynaecology, King's College Hospital, London SE5

GREGORY D O'BRIEN, MRCOG, Rank research fellow

CHARLES RODECK, BSC, MRCOG, senior lecturer/consultant

JOHN T QUEENAN, MD, visiting professor (professor and chairman,

Department of Obstetrics and Gynaecology, University of Louisville

School of Medicine, Louisville, Kentucky)

\section{Effect of labetalol on blood pressure and plasma catecholamine concentrations in patients with phaeochromocytoma}

The safety of labetalol, which has both alpha- and beta-adrenoreceptor blocking actions, in treating phaeochromocytoma ${ }^{1}$ remains controversial since severe sustained hypertension was reported in one patient. ${ }^{2}$ We investigated the effects of labetalol in three patients with phaeochromocytoma. In each case the tumour was localised by computerised axial tomography before starting treatment.

\section{Patients, methods, and results}

The patients gave informed consent for investigation and treatment. Labetalol was given either by mouth (patients 1 and 2) or intravenously (patient 3). Blood pressures were monitored carefully throughout the trial. Orthostatic tests (15 minutes in immobile orthostasis) were made in patients 1 and 2 before and during labetalol treatment and 60 days (patient 1) or five days (patient 2) after surgery. Their blood pressure and heart rate were monitored and blood sampled simultaneously for measuring catecholamine concentrations. The samples were taken one hour after labetalol $100 \mathrm{mg}$ had been given. Similar measurements were made in 12 healthy controls. Catecholamines (adrenaline+noradrenaline) were assayed by a radioenzymatic method. ${ }^{3}$

Before treatment the blood pressures of patients 1,2 , and 3 averaged $184 / 110,184 / 125$, and $162 / 96 \mathrm{~mm} \mathrm{Hg}$ respectively, with very wide variations. In patient 1 giving labetalol $200 \mathrm{mg}$ was followed by a rapid fall of blood pressure to normal. It returned to the initial level after six hours, but was kept normal during the next 10 days by labetalol $100 \mathrm{mg}$ four times a day. The blood pressure in this period averaged 144/92 $\mathrm{mm} \mathrm{Hg}$. In 